\title{
Gynecological cancer: Evolution of its relative frequency
}

\author{
Alfonso Torres-Lobatón ${ }^{1 *}$, Elisa P. Jiménez-Arroyo ${ }^{1}$, Rosalva Barra-Martínez ${ }^{1}$, Juan C. Oliva-Posada', \\ Carla A. Suárez-Juárez ${ }^{1}$, and Fred Morgan-Ortiz² \\ ${ }^{1}$ Oncology Service, Hospital General de México “Dr. Eduardo Liceaga”, Mexico City; ${ }^{2}$ Centro de Investigación en Ciencias de la Salud, Universidad \\ Autónoma de Sinaloa, Culiacán, Sinaloa. Mexico
}

\begin{abstract}
Objective: The objective of the study was to show the relative frequency of gynecological cancers at an oncology unit comparing these results with two previous studies, by highlighting the increase in the number of uterine cancers. Materials and methods: Review the number of cases of gynecological cancers at the Oncology Service of the General Hospital of Mexico from 2016 to 2017, comparing it with two previous periods, 1983-1984 and 2010-2011. Results: We included 931 patients with gynecological cancers, 427 patients with cervical cancer (45.8\%), 274 patients with uterine cancer (29.4\%), and 206 patients with ovarian cancer (22.1\%). When comparing these results with the previous ones, we found that the numbers of cervical cancer decreased from $86.8 \%$ to $57.8 \%$ to $45.8 \%$ ( $p<0.05)$; uterine cancer from $4.5 \%$ to $17.9 \%$ to $29.4 \%(p=0.0001)$; and ovarian cancer from $6.2 \%(p<0.05)$ to $19.7 \%(p=0.185)$. The larger histological group for cervical cancer is adenocarcinomas (18.1\%) and the main histology in uterine cancers is endometrial (86.8\%). From this total, $71.4 \%$ patients are either overweight or obese. About $63.9 \%$ of cases were diagnosed as late-stage cancers. Conclusions: In this series, we detected a decrease in the frequency of cervical cancers, with adenocarcinomas increasing in percentage, and a significant increase in uterine cancers associated with overweightness and obesity. Advanced stages of gynecological cancers were prevalent.
\end{abstract}

Key words: Gynecological. Cancer. Relative. Frequency. Evolution.

\section{Introduction}

Cervical cancer is a public health problem in developing countries because it is often diagnosed in already advanced stages and presents the highest mortality rate among gynecological cancers ${ }^{1,2}$. Conversely, in recent years, the frequency of uterine cancer linked to metabolic syndrome and obesity is on the rise $\mathrm{e}^{3,4}$.

The World Health Organization estimated that by 2018, there would be 190,667 new cases of cancer in Mexico, of which 105,051 (50.9\%) cases would be affecting women. In relation to this total, 20,570 (19.5\%) cases occurred in the reproductive tract with 7869 cases of cervical cancer (38.2\%), $7266(35.3 \%)$ cases of uterine cancer, $4759(23.1 \%)$ cases of ovarian cancer, $422(2.0 \%)$ cases of vulvar cancer, and $254(1.2 \%)$ cases of vaginal cancer ${ }^{5}$.

This article shows the relative frequency of cancers of the female reproductive tract in a high-specialty cancer center for the period 2016-2017. Some of this data is compared with data published in two previous periods. The increase in the number of uterine cancers was highlighted and conclusions were drawn accordingly.

\section{Materials and methods}

During the period 2016-2017, 2185 patients were attended at the Gynecological Tumor Unit of the Oncology

\section{Correspondence:}

*Alfonso Torres-Lobatón

E-mail: drtorreslobaton@prodigy.net.mx
Available online: 12-11-2020

Date of reception: 20-12-2019 DOI: 10.24875/HGMX.20000096
Rev Med Hosp Gen Mex. 2020;83(4):153-158 www.hospitalgeneral.mx 0185-1063/@ 2020 Sociedad Médica del Hospital General de Mexico. Published by Permanyer. This is an open access article under the CC BYNC-ND license (http://creativecommons.org/licenses/by-nc-nd/4.0/). 
Table 1. Gynecological cancer. Relative frequency and age ranges

\begin{tabular}{|l|c|c|c|c|}
\hline Neoplasm & Number of patients & Percentage & Age (minimum-maximum)* & Average age* $^{*}$ \\
\hline Cervical cancer & 427 & 45.6 & $22-92$ & 50 \\
\hline Uterine cancer & 274 & 29.2 & $29-85$ & 55 \\
\hline Ovarian epithelial cancer & 206 & 22.0 & $21-83$ & 47 \\
\hline Vulvar cancer & 22 & 2.3 & $37-90$ & 68 \\
\hline Trophoblastic tumors & 5 & 0.5 & $18-40$ & 29 \\
\hline Vaginal cancer & 2 & 0.2 & $42-68$ & 56 \\
\hline Total & 936 & 99.8 & - & - \\
\hline
\end{tabular}

*In years.

Table 2. Gynecological cancer. Relative frequency in different periods

\begin{tabular}{|l|c|c|c|c|c|c|c|}
\hline \multirow{2}{*}{ Neoplasm } & \multicolumn{2}{|c|}{ (I) 1983-1984 } & \multicolumn{2}{|c|}{ (II) 2010-2011 } & \multicolumn{2}{c|}{ (III) 2016-2017 } & Significance \\
\cline { 2 - 8 } & Number & $\%$ & Number & $\%$ & Number & $\%$ & \\
\hline 1. Cervical cancer & 727 & 86.8 & 632 & 57.8 & 427 & 45.8 & I vs.II $p<0.05$ \\
\hline 2.Uterine cancer & 38 & 4.5 & 197 & 17.9 & 274 & 29.4 & I vs. II $p<0.05$ \\
\hline 3. Ovarian epithelial cancer & 52 & 6.2 & 213 & 19.7 & 206 & 22.1 & I vs. II p $<0.05$ \\
\hline 4. Vulvar cancer & 16 & 1.9 & 22 & 2.0 & 22 & 2.3 & I vs.II $p=0.845$ \\
\hline 5. Vaginal cancer & 4 & 0.4 & 16 & 1.4 & 2 & 0.2 & I vs.II $p=0.032$ \\
\hline Total & 837 & 99.8 & 1,080 & 99.8 & 931 & 99.8 &
\end{tabular}

1: II) versus (III) $p<0.05 ; 2$ : (III) versus (III) $p=0.0001 ; 3$ : (III) versus (III) $p=0.185 ; 4$ : (II versus IIII) $p=0.618$; 5 : (II) versus (III) $p=0.003$.

Service at the General Hospital of Mexico "Dr. Eduardo Liceaga." 1066 patients received a histopathological diagnosis of gynecological cancer: cervical, uterine, ovarian, vulvar, vaginal, and trophoblastic tumors.

According the respective medical records, information was obtained related to the frequency of each neoplasm, patients' age, histopathological varieties, and classification according to that of the International Federation of Gynecology and Obstetrics in its 2009 version $^{6,7}$. For uterine cancers, the body mass index (BMI) was investigated, considering a BMI of 25-29.9 as overweightness and a BMI of $30.0-50$ or more ${ }^{8}$ as obesity. The results obtained regarding the relative frequency of neoplasms and the clinical classification for cervical cancer were compared to those results reported in the previous publications for the years 1983-1984 and 2010-20119,10. These results were subjected to statistical analysis using the Epi-Info ${ }^{\top \mathrm{M}} 6.04 \mathrm{~d}$ system.

\section{Results}

During the period analyzed, 1026 patients were treated. Ninety $(8.7 \%)$ cases corresponded to high-grade intraepithelial neoplasia (CIN 3): eighty-six cases corresponded to cervical cancer, two cases corresponded to vulvar cancer, and two cases to vaginal cancer. The relative frequency and age ranges for invasive cancers are shown in table 1 . The average age for invasive cervical cancers was 50 years, 55 years for uterine cancers, and 47 years for ovarian epithelial cancer.

The relative frequency of gynecological cancers in three different periods (1983-1984, 2010-2011, and 2016-2017) is shown in table 2. The decrease in the frequency of cervical cancers among invasive cancers is highlighted, which represented $86.8 \%$ of neoplasms in $1983-1984$ and $45.8 \%$ in $2016-2017$ ( $p<0.05$ ). In addition, the increase in the frequency of uterine cancers was evident between the period 2010-2011 (17.9\%) 
Table 3. Gynecological cancer 2016-2017. Clinical stage and number of patient ratio

\begin{tabular}{|c|c|c|c|c|c|c|c|c|c|c|c|c|}
\hline \multirow[t]{2}{*}{ Clinical stage } & \multicolumn{2}{|c|}{ Cervical* } & \multicolumn{2}{|c|}{ Uterine** } & \multicolumn{2}{|c|}{ Ovarian } & \multicolumn{2}{|c|}{ Vulvar*** } & \multicolumn{2}{|c|}{ Vaginal**** } & \multicolumn{2}{|c|}{ Total } \\
\hline & Number & $\%$ & Number & $\%$ & Number & $\%$ & Number & $\%$ & Number & $\%$ & Number & $\%$ \\
\hline I & 91 & 24.5 & 141 & 58.2 & 65 & 31.4 & 7 & 31.8 & - & & 304 & 36.0 \\
\hline II & 116 & 31.2 & 28 & 11.5 & 4 & 1.9 & 1 & 4.5 & - & & 149 & 17.6 \\
\hline III & 91 & 24.5 & 46 & 19.0 & 100 & 48.5 & 7 & 31.8 & 1 & 50.0 & 245 & 29.0 \\
\hline IV & 73 & 19.6 & 27 & 11.1 & 37 & 17.9 & 7 & 31.8 & 1 & 50.0 & 145 & 17.2 \\
\hline Total & 371 & 99.8 & 242 & 99.8 & 206 & 99.7 & 22 & 99.9 & 2 & 100 & 843 & 99.8 \\
\hline
\end{tabular}

*CIN 3: 86/513: $16.7 \%)$. No classifiable*: 56/513: (10.9\%). **No. Classifiable: $32 / 274:(13.2 \%) .{ }^{* * *}$ No classifiable:2/24 (8.3\%). ${ }^{* * *}$ VAIN 3: $2 / 4: 50 \%$.

${ }^{*}$ CIN 3: cervical intraepithelial neoplasia Grade 3. ${ }^{* * *}$ VAIN 3: vaginal intraepithelial neoplasia Grade 3.

Table 4. Cervical cancer. Comparative study of its frequency in three different periods

\begin{tabular}{|c|c|c|c|c|c|c|c|}
\hline \multirow[t]{2}{*}{ Clinical stage } & \multicolumn{2}{|c|}{ (I) 1983-1984 } & \multicolumn{2}{|c|}{ (II) 2010-2011 } & \multicolumn{2}{|c|}{ (III) 2016-2017 } & \multirow[t]{2}{*}{ Significance } \\
\hline & No. & $\%$ & No. & $\%$ & No. & $\%$ & \\
\hline (a).I & 104 & 15.8 & 219 & 35.5 & 91 & 24.5 & I versus II $p<0.05$ \\
\hline (b).II & 270 & 41.1 & 190 & 31.0 & 116 & 31.2 & $I$ versus II $p=0.0001$ \\
\hline (c).III & 214 & 32.6 & 144 & 23.3 & 91 & 24.5 & $\mid$ versus II $p=0.0002$ \\
\hline (d).IV & 68 & 10.3 & 63 & 10.2 & 73 & 19.6 & $I$ versus II $p=0.9352$ \\
\hline Total & 656 & 99.8 & 616 & 99.9 & 371 & 99.8 & \\
\hline
\end{tabular}

a: (II) versus (III) $p=0.0003$; b: (II) versus (III) $p=0.945 ;$ c: (II) versus (III) $p=0.738$; d: (II versus III) $p=0.00004$.

and also the period 2016-2017 (29.4\%), $p \leq 0.0001$. This situation led to its rising from third in the period 20102011 to the second position for the period 2016-2017. As presented in table $3,63.9 \%$ of patients in the overall series had advanced neoplasms, (Stages II-IV). The figure includes $75.3 \%$ of invasive cervical cancers, $41.6 \%$ of uterine cancers, $68.3 \%$ of ovarian epithelial cancers, and $68.1 \%$ of vulvar cancers.

\section{Cervical cancer}

A total of 513 patients were treated, of these 86 with CIN1 (16.7\%) and 427 (83.2\%) with Invasive cancer (Table 3). As for histological variants, 419 patients $(81.6 \%)$ presented epidermoid carcinomas; 93 patients (18.1\%) had adenocarcinomas; and one patient $(0.1 \%)$ developed a neuroendocrine carcinoma.

The relative frequency of clinical stages during the analyzed periods is displayed in table 4 . It highlights the decrease in the number of patients treated in the period 2016-2017 in relation to the two previous periods. The decrease in Stage I care in the period 2016-2017 in relation to the period 2010-2011, ( $p=0.0003)$; and the increase in Stage IV frequency observed for the last period: seventy-three cases for 2016-2017 (19.6\%) versus 63 cases for 2010-2011 (10.2\%) ( $p=0.00004)$.

About $62.4 \%$ of the total patients treated hailed from the countryside, $44.5 \%$ from the State of Mexico, and the remainder mainly from the States of Veracruz (7.2\%), Hidalgo (2.4\%), Oaxaca and Guerrero (1.8\% respectively), Morelos (1.5\%), and Michoacán (0.6\%).

\section{Uterine cancer}

274 patients with malignant uterine tumors were treated, of which 250 cases $(91.2 \%)$ corresponded to carcinomas and 24 cases (8.7\%) to sarcomas. Among the carcinomas, endometrial carcinoma occurred in $217 \mathrm{pa}-$ tients $(86.8 \%)$ being the most frequent type of carcinoma. 155 of these patients $(71.4 \%)$ were overweight or obese. The other cases consisted of $15(6 \%)$ cases of uterine papillary serous carcinoma; $10(4.0 \%)$ cases of clear-cell carcinoma; 6 (2.4\%) cases of carcinosarcoma; $1(0.4 \%)$ case of adenosquamous carcinoma, and 1 
$(0.4 \%)$ case of neuroendocrine carcinoma. The latter case involved a 59-year-old patient with an initial diagnosis compatible with carcinosarcoma, who underwent surgery and was classified as stage IIIC2. The immunohistochemistry study established the diagnosis of neuroendocrine carcinoma. The patient received radiotherapy and started with platinum-based chemotherapy in combination with etoposide. Four months after diagnosis, a positron emission tomography-computed tomography scan showed multiple mediastinal and bone metastases. The patient died 6 months later.

Regarding the group of sarcomas, leiomyosarcoma appeared as the most frequent with 13 cases $(54.1 \%)$. It was followed by endometrial stromal sarcoma with nine cases (37.5\%) and adenosarcoma with two cases (8.3\%).

Regarding clinical classification, $58.2 \%$ of cases (141 patients) were classified as Stage I. Seventy-three patients $(30.1 \%)$ were classified as Stages III and IV (Table 3). Ninety-five (67.4\%) out of 141 carcinomas classified as Stage I, corresponded to Stage la and 46 cases $(32.5 \%)$ corresponded to $\mathrm{lb}$. As for 46 cases classified as Stage III, nine (19.5\%) cases showed adnexal metastases (Stage Illa), nine (19.5\%) cases showed parametrial invasion and/or vaginal metastases (Stage IIIB), and 28 (60.8\%) cases showed metastases to regional lymph nodes (Stage IIIc). Regarding the latter, $17(60.8 \%)$ cases were related to pelvic lymph nodes (Stage IIIc1) and 11 (39.2\%) cases were related to the para-aortic lymph nodes.

\section{Ovarian cancer}

246 cases were recorded, of which 206 (83.7\%) cases were epithelial neoplasms (Table 5): 110 (53.3\%) cases of serous carcinoma, $42(20.3 \%)$ cases of endometrioid carcinoma, 25 (12.1\%) cases of mucinous carcinoma, $16(7.7 \%)$ cases of clear-cell carcinoma, and $13(6.3 \%)$ undifferentiated cases.

Twenty-three (9.3\%) cases corresponded to germ cell tumors; regarding this total, $11(47.6 \%)$ cases corresponded to dysgerminomas, 8 (34.7\%) cases of immature teratoma, $3(13.0 \%)$ cases of mixed carcinoma, and $1(4.3 \%)$ case of choriocarcinoma. Seventeen patients were diagnosed with stromal tumors: 11 (64.7\%) cases of granulosa cell tumors and $6(35.2 \%)$ cases of Sertoli-Leydig cell tumors.

About $63.5 \%$ of epithelial tumors were classified as Stages III and IV, and $47.3 \%$ of germ-cell tumors were classified as Stage I. The relationship between histological grade and clinical stages is shown in table 6 .
Table 5. Ovarian tumors

\begin{tabular}{|l|c|c|}
\hline Histopathology & Number of cases & Percentage \\
\hline Epithelial & 206 & 83.7 \\
\hline Germ cell & 23 & 9.3 \\
\hline Stromal & 17 & 6.9 \\
\hline Total & 246 & 99.9 \\
\hline
\end{tabular}

\section{Discussion}

Although a decrease in the number of cervical cancers had already been reported in our Health Centre for 2010-2011: $(57.8 \%)^{10}$ in relation to those published for $1983-1984^{9},(86.8 \%),(p<0.05)$; there was a significant decrease for the period 2016-2017: 57.8\% vs. $45.8 \%(p<0.05)$. However, this disease still ranks high among the leading causes of gynecological cancer admissions in hospitals and health units that serve low-income people in need of social security protection. It is likely that this decrease is related to more efficient health screening services for the disease ${ }^{11}$ and an increase in coverage for its treatment, as the federal government of Mexico has implemented a free cancer care program since 2004.

Unfortunately, advanced clinical stages of the disease still predominate, because more than $60 \%$ of the population that pursues medical treatment at the General Hospital of Mexico "Dr. Eduardo Liceaga," hails from the countryside, where the necessary infrastructure for the comprehensive treatment of this type of cancer is not available ${ }^{12}$.

The increase in frequency, reported at the General Hospital of Mexico "Dr. Eduardo Liceaga", regarding uterine cancer from 2010 to $2011^{10}$ compared to that observed in the years 1983-1984\%: was $17.9 \%$ versus $4.5 \%$ and a rise of $29.4 \%$ in the numbers of this disease for the years 2016 and 2017, placing it second amongst all other gynecological cancers. In contrast, ovarian cancer has gone from $2^{\text {nd }}$ to $3^{\text {rd }}$ place.

We associate this change in the epidemiology of the neoplasms with the increase in obesity in recent years ${ }^{1,4}$. These pathologies increased from 1975 to 2014 , going from $12 \%$ to $33 \%$ in China and $39.5 \%$ to $64 \%$ in Iran. In the US and Mexico, these numbers exceed $60 \%$ for women over the age of $18^{1}$.

There is evidence that endocrine and nutritional lifestyle factors influence the origin of $5 \%$ of cancers in women worldwide, including uterine, ovarian, and 
Table 6. Ovarian tumors. Clinical stage relationship with different histological types

\begin{tabular}{|l|c|c|c|c|c|c|c|c|}
\hline \multirow{2}{*}{ Clinical stage } & \multicolumn{2}{|c|}{ Epithelial* } & \multicolumn{2}{c|}{ Germ cell** } & \multicolumn{2}{c|}{ Stromal } & \multicolumn{3}{c|}{ Total } \\
\cline { 2 - 10 } & No. & $\%$ & No. & $\%$ & No. & $\%$ & No. & $\%$ \\
\hline I & 51 & 24.7 & 9 & 47.3 & 14 & 82.3 & 74 & 33.4 \\
\hline II & 3 & 1.4 & 2 & 10.5 & 1 & 5.8 & 6 & 2.7 \\
\hline III & 94 & 45.6 & 6 & 31.5 & - & - & 100 & 45.2 \\
\hline IV & 37 & 17.9 & 2 & 10.5 & 2 & 11.7 & 41 & 18.5 \\
\hline Total & 206 & 99.7 & 19 & 99.8 & 17 & 99.8 & 221 & 99.8 \\
\hline
\end{tabular}

*Borderline tumors: 21/206 (10.1\%); **No classifiable: $4 / 23(17.3 \%)$.

breast cancer ${ }^{4}$. Obese premenopausal and postmenopausal women are far more likely to develop type I endometrial cancer (up to $40 \%$ ), which is of good prognosis, rather than type II, which is not associated with overweightness and obesity. In addition, type II endometrial cancer has a less favorable prognosis ${ }^{4,13}$. About $86.8 \%$ of the cases presented in this series developed type I endometrial cancer and $71.4 \%$ of these patients were overweight or obese.

The National Institute of Public Health in Mexico published in 2018 that in the past three decades, the prevalence of overweightness and obesity in Mexican children and adults has increased. At present, Mexico is one of the two countries with the highest prevalence of obesity in the world ${ }^{14}$. In 2016, the prevalence of overweightness in adults aged 20 years or older was $72.5 \%{ }^{14}$.

Several studies have been published reporting that overweightness and obesity significantly increase the risk of developing ovarian epithelial cancer ${ }^{4}$ as well as endocervical and adenosquamous epithelial carcino$\mathrm{ma}^{15}$. According to information provided by the Institute of Public Health ${ }^{14}$, this would justify the increase observed from $6.2 \%$ to $22.1 \%$ in ovarian epithelial cancers $^{9,10}$ and $11 \%{ }^{15}$ to $18 \%$ in the numbers of cervical adenocarcinomas reported herein. These factors could also have influenced the presentation of a lower age for ovarian epithelial cancer (47 years) in relation to that of 60 years and older referred to in the literature ${ }^{16-18}$. This observation would also apply to the age of 55 years reported here for uterine cancers ${ }^{8,13}$.

As for the patient with neuroendocrine carcinoma of the endometrium reported here, which represented $0.4 \%$ of the frequency for this site, very few follow-up cases without tumor activity have been reported, which globally do not exceed $30 \%$ at 5 years.
In relation to vulvar, vaginal and trophoblastic tumors, their numbers in terms of frequency and age have remained unchanged in recent years, except for vaginal cancer, whose numbers have decreased from $1.4 \%$ to $0.2 \%(p=0.003)$ and for trophoblastic tumors where there was also a decrease from $1.3 \%^{8}$ to $0.5 \%$.

\section{Conclusions}

The frequency of invasive cervical cancer in relation to other cancers has decreased from $57.8 \%$ in the years 2010-2011 to $45.8 \%$ for the period $2016-2017$. The frequency of cervical adenocarcinoma increased from $11 \%$ observed in the period $2005-2008$ to $18 \%$ for the period 2016-2107.

The frequency of ovarian and uterine cancers increased from $19.7 \%$ and $17.9 \%$ in the period 2010 to 2011 , to $22.1 \%$ and $29.4 \%$, respectively for the years 2016 to 2017. The age of 47 and 55 years shown for these tumors in this series is lower than the age of 60 and older mentioned in the literature.

The increase in the frequency of uterine cancers reported in this series, corresponded to $86.8 \%$ cases of endometrial endometrioid adenocarcinoma. This variety has been associated with being overweight and/or obese, which was present in $71.4 \%$ of the cases studied.

About $63.9 \%$ of patients with reproductive tract cancers, who were treated at the Oncology Service of the General Hospital of Mexico "Dr. Eduardo Liceaga," had late-stage cancers.

\section{Conflicts of interest}

The authors have no conflicts of interest. 


\section{Ethical disclosures}

Protection of human and animal subjects. The authors declare that no experiments were performed on humans or animals for this study.

Confidentiality of data. The authors declare that they have followed the protocols of their work center on the publication of patient data.

Right to privacy and informed consent. The authors declare that no patient data appear in this article.

\section{References}

1. Islami F, Torre AL, Drope MJ, Ward ME, Jemal A. Gobal cancer in women cancer control priorities. Cancer Epidemiol Biomarkers Prev. 2017;26:458-70.

2. Siegel R, Naishadham D, Gemal A. Cancer statistics, 2012. CA Cancer J Clin. 2012:62:10-29.

3. American Cancer Society. Cancer Facts and Figures. United States: American Cancer Society. 2017. p. 21-9.

4. Feng $\mathrm{YH}$. The asociation between obesity and gynecological cancer Gynecol Min Invasive Ther. 2015;4:102-5

5. World Health Organization. Source Globocan 2018, Number of New Cases Both Sexes. International Agency for Research on Cancer. Mexico: World Health Organization; 2018. p. 1-2.

6. FIGO Committee on Gynecologic Oncology. Revised FIGO staging for carcinoma of the vulva, cervix and endometrium. Int J Gynecol Obstet. 2009;105:103-5

7. FIGO Committee on Gynecologic Oncology. Current FIGO staging for cancer of the vagina, fallopian tube, ovary and gestational trophoblastic neoplasia. Int J Gynaecol Obstet. 2009;105:3-4
8. Nevadunsky SN, Arsdale V, Strickler DH, Moadel A, Kaur G, Levitt J, et al. Obesity and age at diagnosis of endometrial cancer. Obstet Gynecol. 2014; $124: 300-6$.

9. Torres LA. Plata NP, Cruz TF, Pérez $H$, García $H$, Román $B$, et al Cáncer ginecológico, 1983-1984. Frecuencia relativa y resultados del tratamiento. Unidad de oncología. Rev Med Hosp Gen. 1987;50:169-77.

10. Torres LA, Amoretti C, Morgan OF. Cáncer ginecológico: evolución de su frecuencia relativa en una institución de alta especialidad. Gac Mex Oncol. 2014;13:222-8.

11. Torres SL, Rojas MR, Escamilla NC, De la Vara SE, Lazcano PE. Tendencias en la mortalidad por cáncer en México de 1980 a 2011. Salud Publ Mex. 2014;56:473-91.

12. Torres LA, Bustamante IJ, Torres RA, Oliva PJ, Morales PM, Román BE. Cáncer cervicouterino. Perfil epidemiológico en 1,217 pacientes. Seguro popular. Ginecol Obstet Mex. 2013;81:71-6.

13. Hacker FN, Friedlander M. Cáncer uterino. In: Oncología Ginecológica de Berek and Hacker. $5^{\text {th }}$ ed. Philadelphia, PA, USA: Lippincott Williams \& Wilkins; 2010. p. 396-7.

14. Campos NI, Cuevas NL, González CL, Hernández BL, Shama LL, González de $\mathrm{CM}$, et al. Epidemiología de la obesidad y sus principales comorbilidades en México. In: Dommarco JA, editor. La Obesidad en México. Estado de la Política Pública y Recomendaciones Para su Prevención y Control. México: Instituto Nacional de Salud Pública; 2018. p. 31-8.

15. Pocrnich S, Ramalingam P, Euscher DE, Malpica A. Neuroendocrine carcinoma of the endometrium; a clincopathologic study of 25 cases. Am J Surg Pathol. 2016;40:577-86.

16. Fujiwara K, Monk B, Devouassoux-Shisheboran M. Adenocaricnoma of the uterine cervix: Why is it different? Curr Oncol Rep. 2014;16:416-22.

17. BereK SJ, Friedlander M, Hacker NF. Cáncer epitelial de ovario, de trompas de Falopio y peritoneal. In: Oncología Ginecológica de Berek and Hacker. 5th ed. Philadelphia, PA, USA: Lippincott Williams \& Wilkins; 2010. p. 455-6.

18. Minig L, Barceló BI, Zorrero C, Velasco P. Dignóstico, estadiaje y diagnóstico precoz del cáncer epitelial de ovario In: Velasco AP, editor. Cáncer de Ovario. España: Permanyer; 2017. p. 14-21. 